\title{
Delayed union of an operated fracture of the femoral neck
}

\author{
Shabir Ahmed Dhar · Naseem U. Gani • \\ Mohammed F. Butt · Munir Farooq · \\ Mohammed Ramzan Mir
}

Received: 25 March 2007 / Accepted: 3 March 2008/Published online: 28 May 2008

(C) Springer-Verlag 2008

\begin{abstract}
Fracture of the femoral neck continues to be a vexing clinical and therapeutic challenge for the orthopedic surgeon. The fracture has a propensity for non-union and avascular necrosis. It is a challenge for the orthopedic surgeon to decide when to intervene in a case with non-union where the implant continues to be in place. We present a case with persistent clinical and radiological non-union signs where the fracture eventually united after 32 months. The case bolsters the view that a continued conservative regime might entail good results in such situations.
\end{abstract}

Keywords Fracture $\cdot$ Neck of femur - Delayed union

\section{Introduction}

Femoral neck fractures remain a difficult clinical problem for orthopaedic surgeons. Attempting to conserve the femoral head often leads to healing complications, while the more predictable prosthetic replacements are associated with poorer function and significant complications [1]. The treatment of these fractures depends on the age of the patient, fracture displacement, bone quality, timing of surgery and activity level of the patient. Displaced fractures in healthy, active patients are best treated by reduction and internal fixation. A good anatomic reduction is mandatory. Femoral neck fractures reduced anatomically are best fixed with three pins or screws [2]. There are however, complications unique to femoral neck fractures

S. A. Dhar $(\bowtie) \cdot$ N. U. Gani · M. F. Butt .

M. Farooq · M. R. Mir

GMC Srinagar, Srinagar, India

e-mail: shabirdhar@yahoo.co.in which are almost impossible to predict. Non-union and avascular necrosis are amongst the most prominent.

Non-union usually can definitely diagnosed within a year of fracture fixation with the same being achieved within 3 months at times [3]. After non-union has been established, intervention is inevitable. The decision to proceed in the management of failed fixation is based on the careful consideration of various factors [4]. In young patients revision internal fixation with cancellous or muscle pedicle bone grafting (vascularised bone graft) or an osteotomy results in useful outcome.

We report a case of non-union of the fracture of the neck of the femur, who refused additional procedures after his non-union had been established. The patient consented to a regular follow up ensuring careful supervision. The fracture eventually healed at 32 months radiographically.

The enrolled patients gave informed consent. The study conforms to the Declaration of Helsinki and was approved by the institutional ethical board.

\section{Case report}

A 38-year old male businessman reported to the out door department of our hospital with a history of a fall from height. Clinical and radiological examination revealed a displaced fracture of the neck of the femur which was graded as Garden type 4 (Fig. 1). The patient was operated within $24 \mathrm{~h}$.

Intraoperatively the Garden alignment index was used as a yardstick of acceptable reduction. The fracture was fixed with 3 AO $6.5 \mathrm{~mm}$ cannulated screws in an inverted triangle. Post operatively the patient was put on walker ambulation. The patient was followed serially till 6 months. From 3 months onward the patient complained 
of persistent but mild groin pain on ambulation which was assisted. Radiographs at 6 months showed non-union. The patients conservative line was continued till 1 year when his symptoms continued and radiologically there was no progress. At this point the patient was advised about the surgical options. He refused surgical intervention preferring the use of a stick. However he consented to a regular 2 monthly follow up. The implant in the mean time had not displaced. Twenty-six months into the post operative followup the patients pain subsided and radiographs started showing signs of union. A radiograph taken 32 months after the fixation showed full union. The patient at this point was asymptomatic (Figs. 2, 3).

\section{Discussion}

Non-union after femoral neck fracture can be defined as a lack of radiographic evidence of union 6 months after the fracture [5]. Delayed or non-union often manifests as continued pain with weight bearing beyond 3 months post fixation [1]. Incidence of non-union of femoral neck fractures has been reported to be between 2 and $22 \%$ and generally becomes apparent within 1 year [6-9]. The risk of non-union is even greater with displaced fractures.

Anatomical reduction and rigid internal fixation are the two important surgeon controlled factors that may contribute to outcome. Garden alignment index is the yard stick of reduction [10]. Most authors recommend fixation with three cannulated screws usually in an inverted triangle [11]. The implant in our case was placed as per the recommendation [12]. The fracture itself was anatomically reduced.

Once non-union is established, intervention is usually required. There is no time frame in literature regarding this intervention. The preferred treatment for symptomatic non-

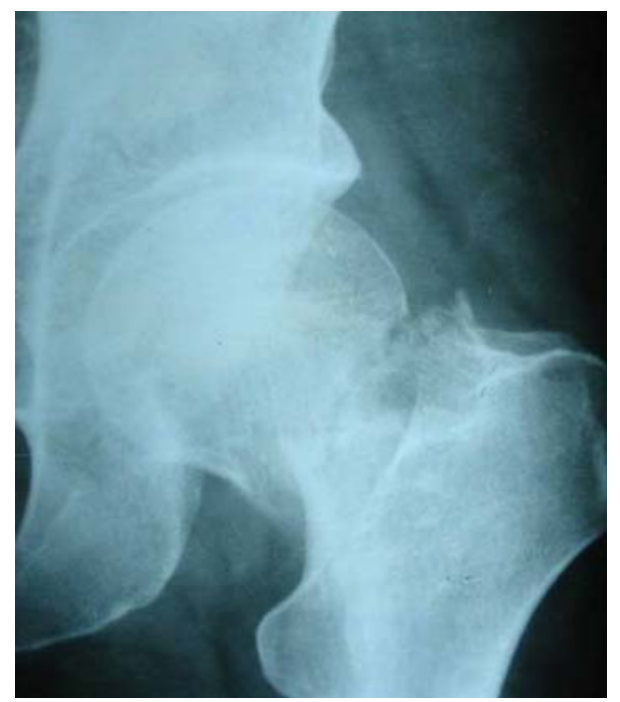

Fig. 1 Garden 4 type fracture of the neck of the femur

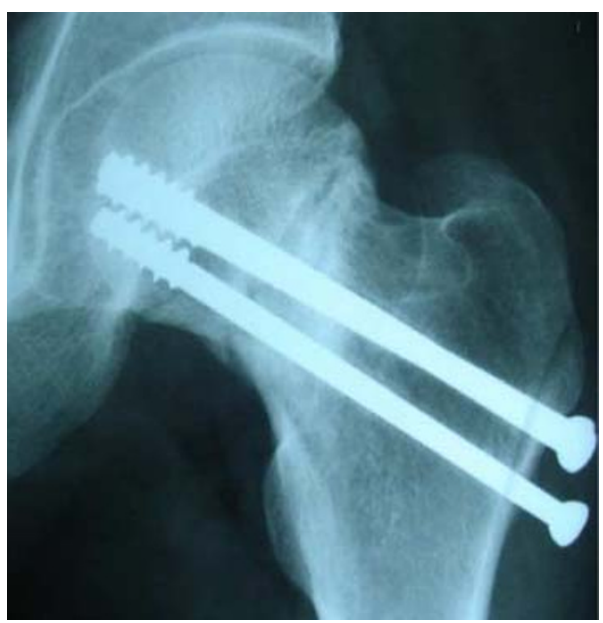

Fig. 2 Showing persistent non-union at 2 years

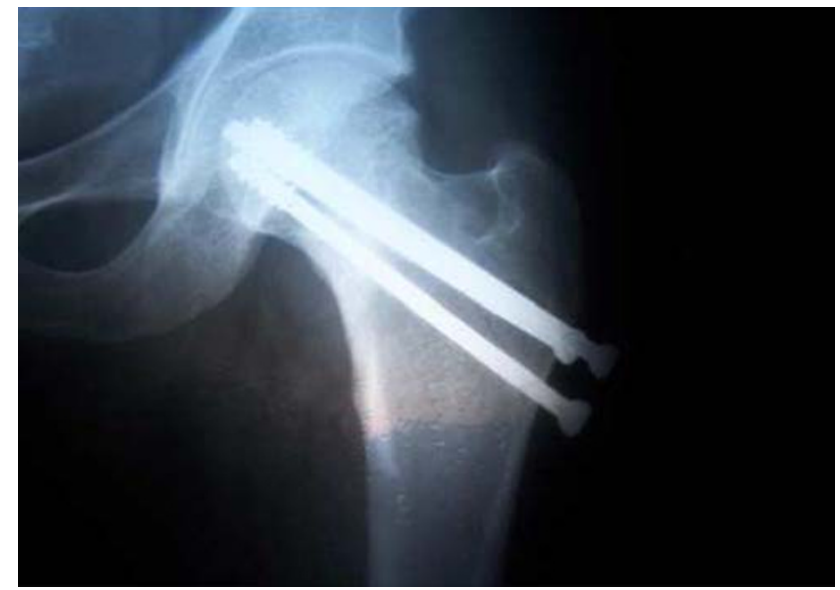

Fig. 3 Radiograph at 32 months depicting union

unions in the elderly is prosthetic replacement. In the young active patients, femoral head salvage is almost always indicated [13]. If failure is due to technical errors, revision open reduction and internal fixation may be adequate. In most cases however an osteotomy is done [14].

The timing of intervention however is debatable. Our case demonstrates that as long as the implant is holding and the patient is regularly followed up good results might be expected in cases as far as 32 months into the post fixation period.

Conflict of interest statement The authors declare that they have no conflict of interest related to the publication of this manuscript.

\section{References}

1. Schmidt AH, Swiontkowski MF (2002) Femoral neck fractures. Orthop Clin North Am 33:97-111

2. Swiontkowski MF, Harrington RM, Keller TS, et al (1987) torsion and bending analysis of internal fixation techniques for 
femoral neck fractures. The role of implant design and bone density. J Orthop Res 5:433-444

3. David G (1998) LaVella. In: Campbell Operative orthopaedics, Canale ST, 9th edn. vol 3, Mosby, pp 2579-2629

4. Koval KJ, Zuckerman JD (2005) Hip fractures. A practical guide to management. Springer, New York, pp 49-127

5. Zuckerman JD (1990) Comprehensive care of orthopaedic injuries in the elderly. Urban and Schwarzenberg, Baltimore

6. Arnold WB, Lyden JP, Minkoff J (1974) Treatment of intracapsular fractures of the femoral neck. JBJS 56-A:254-262

7. Banks HH (1962) Factors influencing the results in fractures of the femoral neck. JBJS 44-A:931-964

8. Banks HH (1974) Non union in the fractures of the femoral neck. Orthop Clin North Am 5:865-885
9. Chapman MW (1975) Treatment of intracapsular hip fractures by Deyerle method. JBJS Am 57:735-744

10. Garden RS (1971) Malreduction and AVN in subcapital fracture of the femur. JBJS[Br] 53:183-197

11. Bray TJ (1997) Femoral neck fracture fixation. Clinical decision making. Clin Orthop 339:20-31

12. Baumgartner MR, Higgins TF. In: Rockwood and greens. Fracture of the adults, vol P. Williams and Wilkins, pp 1579-1634

13. Meyers MH (1980) The role of posterior bone grafts in failed neck fractures. Clin Orthop 150:143-146

14. Marti RK, Schuller HM, Raaymakers EL (1989) Intertrochanteric osteotomy for non union of the femoral neck. JBJS 71-b:782-789 